\title{
Microgrids Connected to the Residential grid for Energy Management Utility Fuzzy Logic Controller Employed Hybrid Electric Vehicles
}

\author{
S. Prakash, K. Sakthivel, Anitha. S
}

on the battery storage capacity. In order to provide the efficient Abstract: - In our research design presents the model of power driven the system is controlled with fuzzy logic control managing the energy for residential purpose and for hybrid vehicle system in microgrid connected module. The major aim of simultaneously. This system integrated with reusable energy storage introducing the fuzzy logic control scheme in order to reduce or system such as PV panel and battery. Our energy management minimize the fluctuations and to reduce the complexity also it system approaches the goal to satisfy power needed and to minimize produces the sum of net average power from the both the

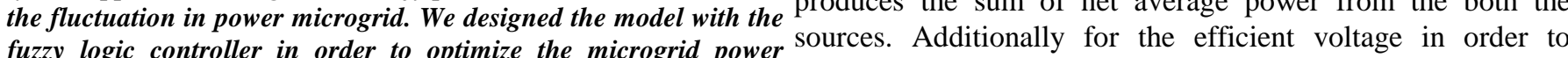
constantly. The energy sources retrieved and given to hybrid electric maintain constant velocity the system is coupled with the vehicle and residential purpose. Now a day's most of the vehicles are bidirectional converter to DC output link and hence the output hybrid mostly runs on either in fuel or by electric energy else by both driven voltage is constant[1], [3],[5]

energy sources. In order to achieve the maximum power throughput, we proposed the bidirectional converter is connected with PV panel and microgrid. The designed fuzzy logic controller to manage the lifetime of battery and to provide the constant discharge. The entire vehicle setup module is connected to microgrid.

Keywords: microgrid, fuzzy logic controller

\section{INTRODUCTION}

RENEWABLE ENERGY source such as Photovoltaic cell or solar PV used for electric energy generation. In modern vehicle the battery plays important role in hybrid power system applications. Hybrid Electric Vehicle must have driving parameters such as acceleration with braking system running with constant velocity also which needs the additional applications such as the efficient bidirectional converter to manage the battery level to charge and discharge hence the performance and efficiency is increases. Solar PV integrated with the power transmission microgrid simultaneously used for the purpose of residential and for hybrid vehicle. Here the external storage batteries are connected with the vehicle in order to provide constant power to loads. The compensating power driven from the microgrid given to the connected load is constantly managed. The content explains about the two key building blocks such that photovoltaic and microgrid system. The power driven from the solar i.e., PV module is maximum from the solar energy also the alternative supply from the microgrid system. The external battery storage source is connected with the solar PV module in such a way the its connected to the hybrid vehicle. Maximum power can be drawn by the method of Maximum Power Point Tracking system and neural Network Multi model. In modern hybrid vehicles uses multi energy driven system either by fuel or by electrical power or both the energy. These integrated system needs constant velocity, efficient braking system and energy management based

Revised Manuscript Received on August 22, 2019.

M.Prakash, Department of EEE,Bharath Institute of Higher Education \& Research,TamilNAdu Email: prakashacademics@gmail.com

K.Sakthivel, Department of EEE,Bharath Institute of Higher Education \& Research,TamilNAdu Email: ksakthivelme@ gmail.com

Anitha.S, Department of EEE,Bharath Institute of Higher Education \& Research,TamilNAdu Email: anithababs@gmail.com

\section{METHODOLOGY}

The new systematic design with the aim of improving the efficiency and performance designs as well as simplifying the Fuzzy Logic Controller complexity (i.e. to reduce the controller inputs number and its rule-base), this work presents a new Fuzzy logic-based Energy Management System of only two-inputs, one-output and with the 25-rules. As it will be seen, the key factor of the new design is to consider the MG Energy Rate-of-Change (ERoC) as an input in order to anticipate the system behavior. The design methodology will follow the procedure and the optimization process developed (i.e. off-line controller parameter setting process). A comparison of SMA strategy, Fuzzy EMS-NPT, and Fuzzy EMS-ERoC approaches will be presented at simulation level, whereas the features of this last one will be tested on a real residential MG. [8],[ 10],[12]

\section{SYSTEM MODELLING}

In our research our model consist of major module such that in this implementation method consist of

(a) Fuzzy Logic Controller

(b) Bidirectional converters

Fuzzy Logic Controllers:

In our implementation method Fuzzy logic method plays important role this context explains about the major role of this logic implementation here in order to minimize the peak power fluctuation in the grid and interfaced devices. Also to reduces the system complexity and to suggest the average value i.e., the sum of the average value of grid power. The basic application of the fuzzy logic in power system is to provide the necessary process control also for the identification in order to diagnosis the problem and to estimation of the required power energy sources. This system is quite implemented with the numeric input and output mapping with the artificial neural network. This system also provide necessary user interface for the specific functionality. Fuzzy logic

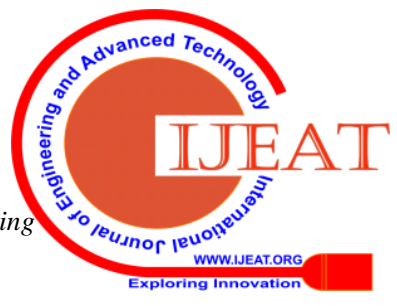


system provides a vast application over power system design and drives design in order to give the optimum response and hence the entire system which is efficient in order to enhance the performance of the electrical generator speed such that wind turbine system which provides the maximum power output. The major advantages of our system provided with the fuzzy logic solution it provides necessary possible solution systematically when the operation of the system based on systematic rules. [2 ],[ 4],[6]

\section{MAXIMUM POWER POINT TRACKING ALGORITHM}

In this research model we approach and implemented the power tracking algorithm called MPPT algorithm is Maximum Power Tracking Algorithm which is suitable for the PV solar module and the bidirectional DC converter in order to track or drive maximum power from the PV module also from the connected grid to manage the power supply to the connected load source such as the Hybrid electric vehicle and the residential load. The proposed MPPT algorithm is successfully designed and implemented in our research design module. In our research concerns about case study in MPPT algorithm.

The classification of MPPT algorithm:
(a) On-Line Methods
(b) Off-Line Methods

These are the major classifications in this algorithm used for driving maximum power sources.

\section{A. FUZZY LOGIC CONTROLLER MODULE:}

The following module described about the Fuzzy Logic Control scheme.

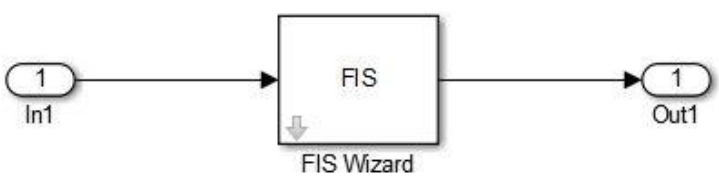

Figure1:Fuzzylogic controller

The above circuit diagram shows the design of fuzzy logic controlled has been designed using the MATLAB. Thus the functional units of input and the output were successfully verified. [7],[9], [11]

Bidirectional Converters:

As for as our new research concern with the typical module called bidirectional converters. Several topologies have been referred by the case studies also with theoretically with extensive references these converters plays systematic role in power systems. This method is applied in the electric grid and hybrid vehicle system. [13], [15], [17]

There are two major classifications witch divided into

i) ON board Bidirectional Converters.

ii) OFF board Bidirectional Converters

These consist of larger power rating with defined structure of specific size typically in such a way that it's designed for the purpose of rapid charging and discharging purpose. As mentioned above two major classifications in most of the applications OFF board bidirectional converters are used for rating and to increase the efficiency.

\section{b. PROPOSED SYSTEM DESIGN:}

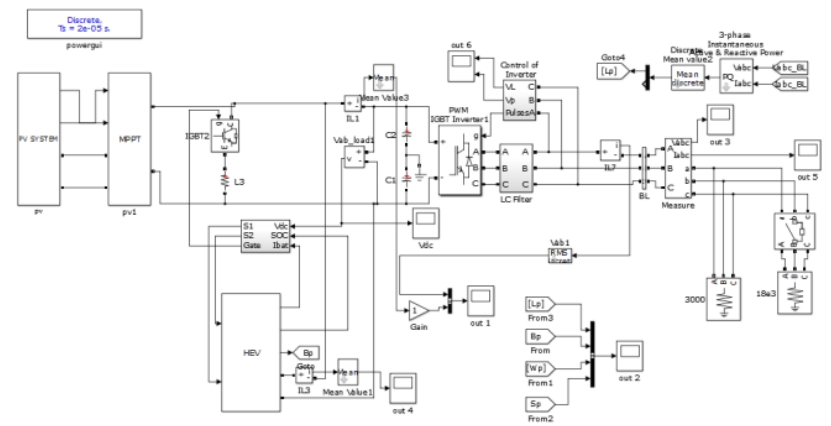

Our proposed implementation design described here we designed the module with the photovoltaic cell and the gird with any electrical source as the main input sources. They are arranged in such a way that connected in series with the battery unit for the efficient power sources. Here we introduce the bidirectional converter unit connected with the battery module in order to provide the compensated power supply. The entire system provides the sufficient power supply to multiple energy sources [14],[16], [18]

This system is enhanced with the maximum power point tracking algorithm in order to track or receive the maximum gain to the connected load. The power can deliver to the residential load and the Hybrid vehicle simultaneously. There by the system is capable for maintaining the constant power sources. In order to provide the power supply with minimum and neglected fluctuation in grids the Fuzzy logic controller has been implemented in our proposed

\section{c. PV MODULE DESIGN}

The design structure shows the module design of the PV module.

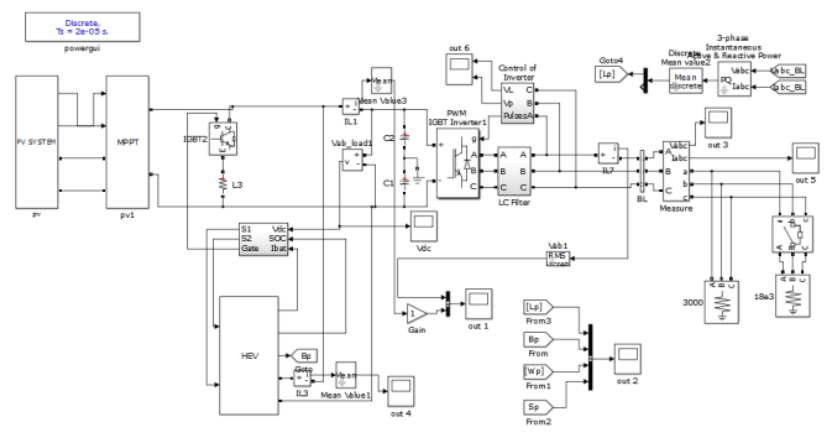

Figure 3: Proposed System design

Our proposed implementation design described here we designed the module with the photovoltaic cell and the gird with any electrical source as the main input sources.

They are arranged in such a way that connected in series with the battery unit for the efficient power sources. Here we introduce the bidirectional converter unit connected with the battery module in order to provide the compensated power supply. The entire system provides the sufficient power supply to multiple energy sources

This system is enhanced with the maximum power point tracking algorithm in order to track or receive the maximum gain to the connected load. The power can deliver to the residential load and the Hybrid 
vehicle simultaneously. There by the system is capable for maintaining the constant power sources. In order to provide the power supply with minimum and neglected fluctuation in grids the Fuzzy logic controller has been implemented in our proposed[19],[21]

\section{PV MODULE DESIGN:}

The design structure shows the module design of the PV module.

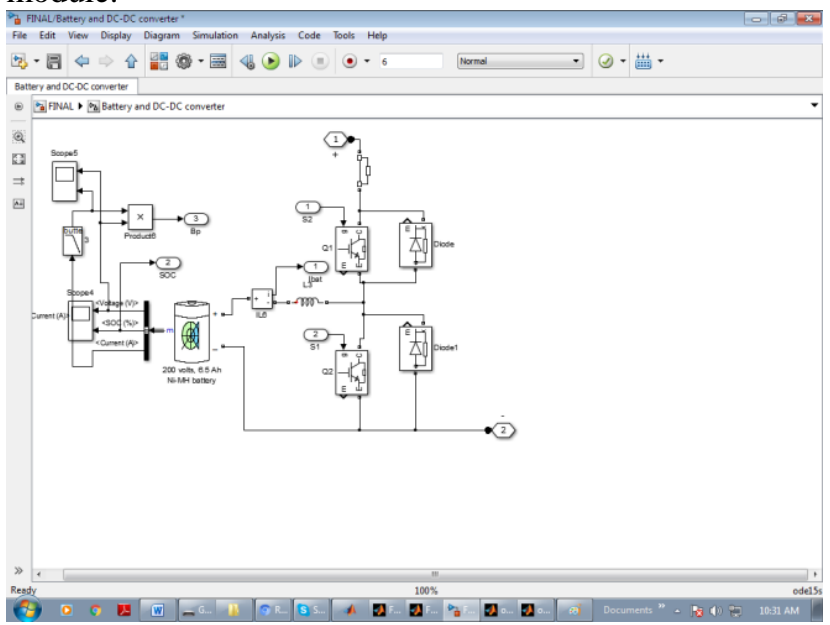

The above design methodology clearly describing about the design and implementation of PV module. As for as for our design purpose we have used the designing tool called MATLAB-Simulink tool, in our proposed method PV module plays important role in power generation scheme in order to provide reliable and constants in stability on energy sources. While designing the PV module the factors must be consider that it must be capable to provide the maximum energy source with relevant output load the simulation is carried out with the modular design

\section{E. VEHICLE BATTERY CHARGING CIRCUIT}

The below design module shows the vehicle battery charging circuit

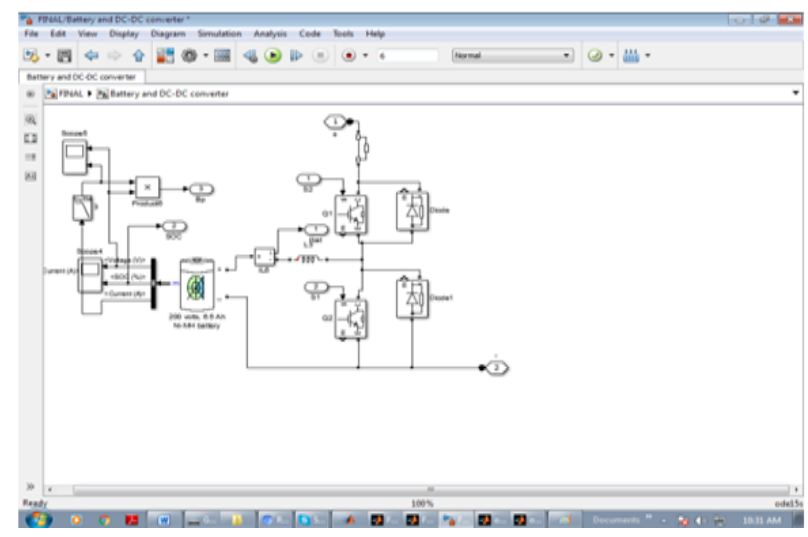

Figure 5.: Vehicle battery charging circuit

The above circuit diagram shows the module of the vehicle battery charging unit, on considering the charging system such as the battery the parameters must be consider must satisfy the high charging capacity in order to meet the necessary requirement to manage the power consumed by the connected load. Also it must have good charging and discharging capabilities with reduced short circuit.

\section{RESULT \& DISCUSSION:}

\section{OUTPUT VOLTAGE:}

The below design shows the Output voltage

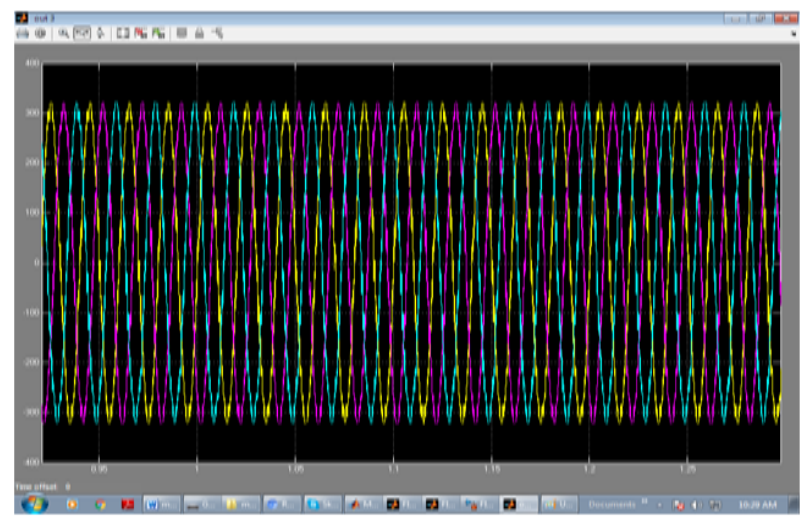

Figure (5): OutputVoltage

\section{OUTPUT CURRENT}

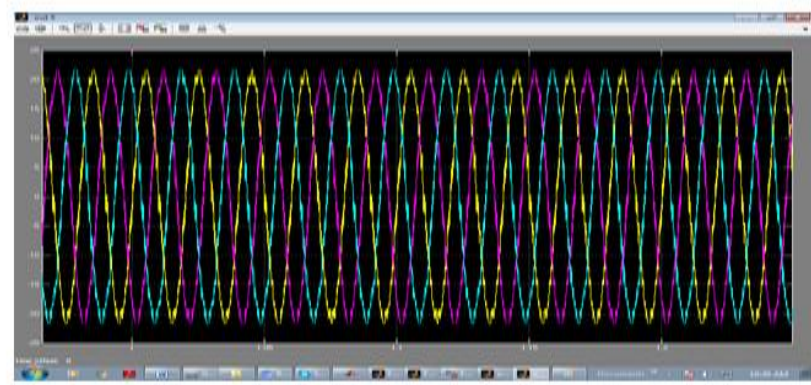

Figure (6): Output Current

\section{INVERTER VOLTAGE:}

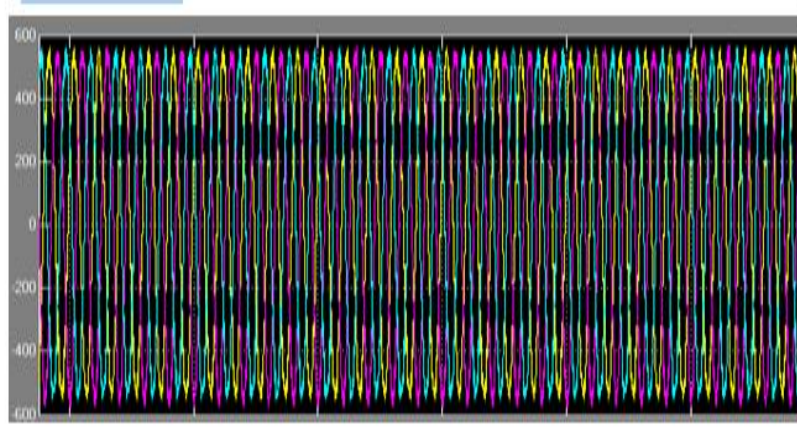

\section{Figure (7): Invetter Voltage}




\section{LINK VOLTAGE}

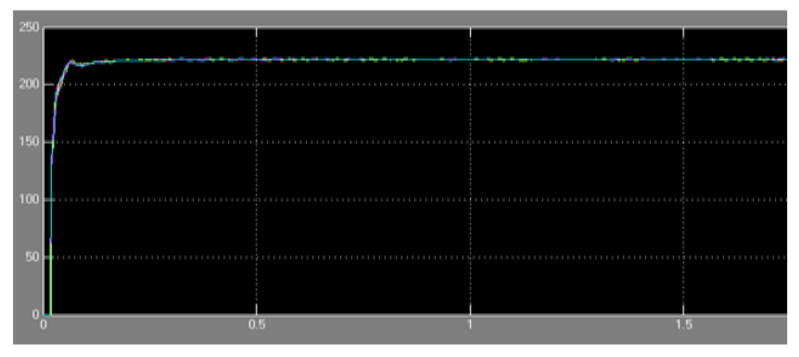

Figure (8): DC Link voltage

The above all graphical representation shows the simulation output for our research which has been designed and simulated by the simulating tools called MATLAB Simulink.

\section{CONCLUSION}

This simulated research has presented the new design of the power transmission micro grid connected multiple load such that residential load and the hybrid electric vehicle connected parallel in order to it. Our energy utility system integrated with Photovoltaic module and applied algorithm for driving maximum power usingMaximum Power Point Tracking algorithm. Hence the system is more efficient in our first phase research. Here we proposed the fuzzy logic based maximum power point tracking for the micro grid applications connected with the multiple loads allows bidirectional. Our system provides high efficient output rather than the existing methodologyon comparing with the other approaches with same goal we analyzed the simulation using real time data has been studied for the future improvements. However the former concept with drawbacks is consequently reduced in our design research. Furthermoreresearch in future our system can utilize for the Hybrid power generation and management process with renewable sources, Hence demand in electrical energy is probably reduces also abandoned utilization of electrical energy can be compensated. Thus our system can able to maintain and give the constant output stability more than sufficient level.

\section{REFERENCES}

1. Sharma, R.K., Irusapparajan, G. \& Periyaazhagar, D. 2019, "Three-phase symmetric cascading Z-source seven levels multilevel inverter excited by multi carrier sinusoidal pulse width modulation scheme", International Journal of Innovative Technology and Exploring Engineering, vol. 8, no. 10, pp. 4269-4274.

2. Velavan, R., Bharanidharan, S. \& Sheeba, B. 2019, "EMF pollution Causes, effects and protection", International Journal of Innovative Technology and Exploring Engineering, vol. 8, no. 9 Special Issue 3, pp. 1166-1168.

3. Saravana, S., Balaji, S., Arulselvi, S. \& John Paul Praveen, A. 2019, "Reliable power quality monitoring and protection system", International Journal of Innovative Technology and Exploring Engineering, vol. 8, no. 9 Special Issue 3, pp. 644-645.

4. Tamil Selvan, S. \& Sundararajan, M. 2019, "Performance Parameters of 3 Value 8t Cntfet Based Sram Cell Design Using H-Spice", International Journal of Recent Technology and Engineering, vol. 8, no. 2 Special issue 5, pp. 22-27.

5. Jac Fredo, A.R., Abilash, R.S., Femi, R., Mythili, A. \& Kumar, C.S. 2019, "Classification of damages in composite images using Zernike moments and support vector machines", Composites Part B: Engineering, vol. 168, pp. 77-86.

6. Kathiravan, P. \& Govindaraju, C. 2019, "Design and evaluation of ultra gain isolated DC-DC converter for photovoltaic system",
International Journal of Engineering and Advanced Technology, vol. 8, no. 5 , pp. 2646-2651.

7. Kripa, N., Vasuki, R. \& Kishore Kanna, R. 2019, "Realtime neural interface controlled au-pair BIMA bot", International Journal of Recent Technology and Engineering, vol. 8, no. 1, pp. 992-994.

8. Mohanraj, Meenaa Kumari, M., Philomina, S. \& Jasmin, M. 2019, "In-situ humidity measurement of hydrogen fuel cell car using MEMS sensor", International Journal of Recent Technology and Engineering, vol. 8 , no. 1 , pp. 41-43.

9. Velmurugan, T. \& Prakash, S. 2019, "Artificial intelligent based distribution automation of swift fault detection isolation and power restoration for HT network", International Journal of Innovative Technology and Exploring Engineering, vol. 8, no. 6, pp. 1-6.

10. Dwarakesh, K. \& Prem Kumar, G. 2019, "Five-level inverter based sequential boost system using fuzzy logic controller", International Journal of Innovative Technology and Exploring Engineering, vol. 8, no. 6 , pp. $12-19$

11. Anne Gifta, A. \& Hemavathi, G. 2019, "Analysis of grid tied solar PV system using ANFIS Algorithm", International Journal of Innovative Technology and Exploring Engineering, vol. 8, no. 6, pp. 312-316.

12. Jayavel, R., Rangaswamy, T.R. \& Prakash, S. 2019, "Efficient grid management system with renewable and conventional power sources", International Journal of Innovative Technology and Exploring Engineering, vol. 8, no. 6, pp. 287-289.

13. Hemavathi, G. \& Maheshwaran, S. 2019, "Proportional resonant controlled high gain step-up converter system with improved response", International Journal of Innovative Technology and Exploring Engineering, vol. 8, no. 6, pp. 317-323.

14. Periyaazhagar, D. \& Irusapparajan, G. 2019, "Design and completion of asymmetric single phase 27 level cascaded mli for various pwm scheme", International Journal of Innovative Technology and Exploring Engineering, vol. 8, no. 6, pp. 792-797.

15. Mahalakshmi, V. \& Vijayaragavan, S.P. 2019, "PV based power electronic converters for high voltage DC applications", International Journal of Recent Technology and Engineering, vol. 7, no. 6, pp. 670-674.

16. Irusapparajan, G., Periyaazhagar, D., Prabaharan, N. \& Rini Ann Jerin, A. 2019, "Experimental verification of trinary DC source cascaded h-bridge multilevel inverter using unipolar pulse width modulation", Automatika, vol. 60, no. 1, pp. 19-27.

17. Sangeetha, G., Sherine, S., Arputharaju, K. \& Prakash, S. 2019, "On Line Monitoring of Higher Rated Alternator using Automated Generator Capability Curve Administer", Proceedings of the IEEE International Conference on \&amp;quot;Recent Trends in Electrical, Control and Communication\&amp;quot;, RTECC 2018, pp. 176.

18. Bycil, V.J. \& Wiselin, M.C.J. 2019, "Modeling and analysis of vibration energy harvesting system using piezo stack", International Journal of Mechanical and Production Engineering Research and Development, vol. 9, no. Special Issue 1, pp. 523-533.

19. Sripada, A., Warrier, A., Kapoor, A., Gaur, H. \& Hemalatha, B. 2018, "Dynamic lateral balance of humanoid robots on unstable surfaces", International Conference on Electrical, Electronics, Communication Computer Technologies and Optimization Techniques, ICEECCOT 2017, pp. 539.

20. Srinivasan, S., Thirumalaivasan, K. \& Sivakumaran, T.S. 2018, "Performance evaluation of double-output luo converters", Journal of Advanced Research in Dynamical and Control Systems, vol. 10, no. 10 Special Issue, pp. 870-878.

21. Karthikayen, A. \& Selvakumar Raja, S. 2018, "A skellam distribution inspired trust factor-based selfish node detection technique in MANETs", Journal of Advanced Research in Dynamical and Control Systems, vol. 10, no. 13, pp. 940-94 


\section{AUTHORS PROFILE}

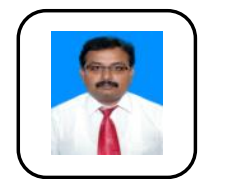

M.Prakash,Professor Department of EEE,Bharath Institute of Higher Education \& Research,TamilNAdu

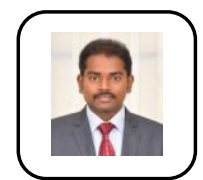

K.Sakthivel, Assistant Professor Department of EEE,Bharath Institute of Higher Education \& Research,TamilNAdu

Anitha.S, Assistant Professor Department of EEE,Bharath Institute of Higher Education \& Research,TamilNAdu 